\title{
Multi-objective Conjunctive Use Optimization
}

\author{
H. C. Fayad ${ }^{1}$ and R.C. Peralta ${ }^{1,2}$ \\ ${ }^{1}$ Biological and Irrigation Engineering Department, Utah State University, Logan, \\ UT 84322-4105; PH (435) 797-2786; FAX (435) 797-1248; email: fayadh@aol.com \\ ${ }^{2}$ Water Dynamics Laboratory, Utah State University Research Foundation; and \\ Biological and Irrigation Eng. Dept., USU; email: Richard.peralta@usurf.usu.edu
}

\begin{abstract}
This paper presents a simulation/optimization model based on artificial neural networks and genetic algorithms for solving multi-objective conjunctive water use problems. The model simulates and optimizes water flows in a hydraulically connected reservoir-stream-aquifer system. It is a powerful tool to help water managers and authorities in developing conjunctive water management strategies and evaluating tradeoffs between conflicting goals.
\end{abstract}

\section{Introduction}

Coordinated optimization of surface water and groundwater resources can enhance water supply reliability by providing water sources having distinctly different costs and constraints (Lettenmaier and Burges, 1997). The integrated use of hydraulically connected groundwater and surface water is referred to as conjunctive use.

Most simulation/optimization (S/O) models for stream- aquifer system management have not included reservoir management rules and detailed interactions between reservoir storage, water use, and groundwater. Mathematical representations of stream-aquifer interactions range from linear differential equations to complicated nonlinear formulations (Morel-Seytoux and Zhang, 1990).

Linear stream-aquifer systems are addressable using linear systems theory via superposition. Nonlinear systems, such as unconfined aquifers, can be treated as linear if the saturated thickness is large compared with the hydraulic drawdown (Reilly et. al., 1987). Many researchers adopted linear treatment to satisfactorily address nonlinear systems (Jones et. al., 1987; Mueller and Male, 1993). Others used cycling to adapt linear systems theory to optimize nonlinear groundwater problems (Gharbi and Peralta, 1994; Peralta and Aly, 1993; Takahashi and Peralta, 1995). 
Several studies discuss optimizing conjunctive use (Peralta et. al., 1990; Yan and Smith, 1994; Peralta et. al., 1995; Wang et. al., 1995; Ejaz and Peralta, 1995). Belaineh et. al. (1999) developed an S/O model that integrated linear reservoir management rules, simulated detailed stream-aquifer seepage, included water delivery to water users via branching canals, and maximized conjunctive use. The model generated linear decision parameters, employed linear programming, and used cycling to ensure convergence to optimality for nonlinear flow systems.

In nonlinear programming, the convexity of both the objective function and feasible region cannot always be ensured. Therefore, a computed optimal solution is not always guaranteed to be globally optimal. Moreover, nonlinear programming methods must compute derivatives with respect to decision variables and may consume much CPU time to do that. Consequently, many researchers investigated the use of alternative optimization techniques for groundwater management. Such methods include simulated annealing (Rizzo and Dougherty, 1994), artificial neural networks (Rogers and Dowla, 1994; Rogers et. al., 1995; SSOL, 2003), and genetic algorithms (McKinney and Lin, 1994; Ritzel et. al., 1994; Rogers and Dowla, 1994; Peralta et. al., 2003). These new techniques do not compute derivatives, which can be difficult to estimate in nonlinear and non-convex groundwater problems.

Water resources projects are often constructed to serve multiple objectives. Many water resource planning studies include multiple objectives (Peralta and Killian, 1985; Ritzel et. al., 1994; Cieniawski et. al., 1995; Ejaz and Peralta, 1995). Multiobjective (MO) optimization permits evaluating tradeoffs between conflicting goals and aids in identifying acceptable compromise solutions. Sometimes multiple objectives have been combined to form a scalar objective function, usually through a weighted sum of the multiple objectives, or by turning objectives into constraints with associated thresholds and penalty functions. Other methods for MO handling include $\epsilon \varepsilon$-constraint method and goal programming. More recent studies have tried a different approach to multi-criteria optimization with genetic algorithms (McKinney and Lin, 1994; Ritzel et. al., 1994; Cieniawski et. al., 1995; Rogers et. al., 1995).

The primary objective of this study was to develop a S/O model for managing dynamic hydraulically connected surface reservoir-stream-aquifer systems. The model addresses multiple objectives and uses genetic algorithms and artificial neural networks techniques in order to model complex nonlinear stream-aquifer systems.

\section{Study Area Description}

The study area was modified from that of Cheng and Anderson (1993)to better illustrate conjunctive management (Fig. 1). Features include a stream, an agricultural area, a multipurpose reservoir, and wells pumping from a homogeneous anisotropic two layer aquifer. The total study area size is $11.15 \times 10^{6} \mathrm{~m}^{2}$. The stream is in excellent hydraulic connection with the aquifer and has an average width of $9.1 \mathrm{~m}$. The $18.3 \mathrm{~m}$ deep lake is in saturated hydraulic connection with groundwater. One diversion from the lake and two diversions are from the stream flowing from the lake. 
The wells extract from the confined aquifer layer only. The stream penetrates only the unconfined aquifer layer. Aquifer recharge occurs only to the top grid layer. Besides the agricultural water demand, water demand for municipal and industrial use is also considered. Water is assumed delivered through pipes and lined concrete canals; therefore, conveyance losses are considered insignificant for this study.

Assumptions are as follow. Water losses from the irrigated field depicted in figure 1 are $30 \%$ of the total applied water, $18 \%$ of which goes to deep percolation and $12 \%$ goes directly to surface water return flow. The irrigated field receives water from the first stream diversion. The pumping wells, the reservoir diversion, and the second stream diversion deliver water to four agricultural areas and one small rural town.

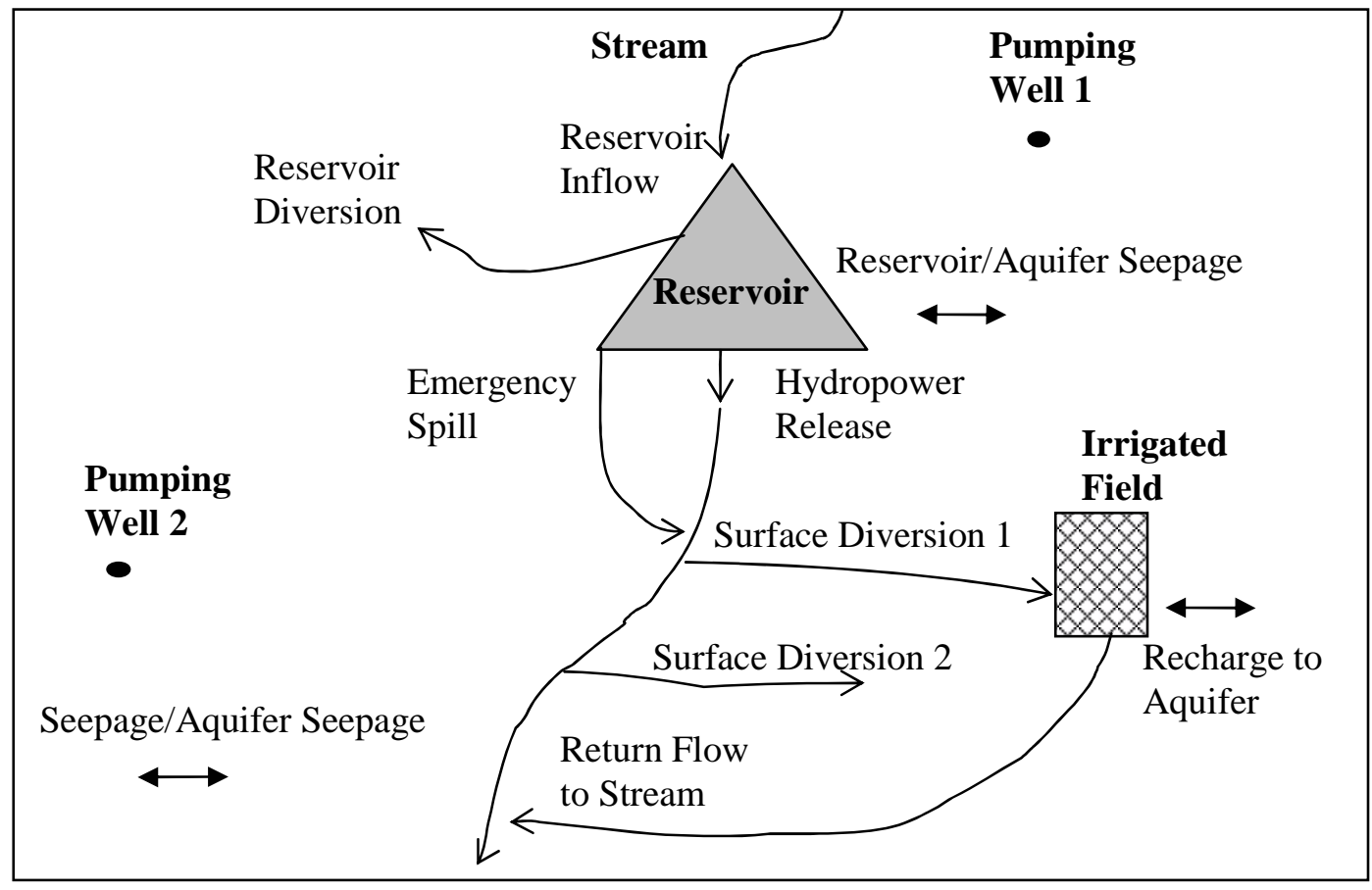

Figure 1. Conceptual View of the Hypothetical Study Area.

Return flows and recharges from these four other agricultural areas are treated outside the aquifer basin. Municipal and industrial water is fully consumed, or discharged after treatment outside the basin. The total domestic water consumption is 181.7 $\mathrm{m}^{3} /$ day. The 6-month planning period was divided into three stress periods of equal duration. The hydropower turbine elevation is $20.12 \mathrm{~m}$, providing $9.5 \mathrm{~m}$ of head.

\section{Optimization Problem Formulation}

We used three objectives: 1) maximize water provided from wells plus surface water diversions, 2) maximize hydropower production and 3) minimize total water cost. Surface diversions are from streams and from the surface water reservoir. Water is released from the lake through turbines to produce hydropower. Costs are those of 
moving water from stream, lake, or aquifer to its destination. Cost is nonlinear because it is a function of heads, which are affected by decision variables.

Each of the three objectives is subject to the same set of constraints. Constraints include bounds on groundwater pumping, stream diversion, aquifer head, and stream reach outflow. Constraints ensure that: 1) groundwater pumping and surface water diversions are adequate to meet total water demand, 2) aquifer heads are acceptable and 3) well pumping rates are within appropriate limits. These constraints are intended to enforce natural conditions, legal rights and management goals.

\section{Optimization Scenarios}

Three scenarios are used to demonstrate the ability of the model to simulate and optimize a multi-objective conjunctive water use problem. Scenario 1 demonstrates simultaneous maximization of two objective functions: maximize total water delivered and maximize hydropower production. These are non-commensurate and conflict with each other. Maximizing total delivered water leads to maximizing water diverted from the reservoir. Therefore, the amount of water available from the turbine to produce hydropower decreases. This leads to a drop in hydropower production.

Scenario 2 demonstrates simultaneous optimization of maximization and minimization objective functions. The first objective maximizes total water diverted and the second objective function minimizes total cost of delivering water. Operating cost includes pumping cost, stream diversion cost and reservoir diversion cost. .

Estimated water costs are: $\$ 4.05$ per 100 cubic meters of water from wells, $\$ 0.81$ per 100 cubic meters of stream water, and $\$ 0.97$ per 100 cubic meters of reservoir water.

Scenario 3 simultaneously optimizes all three objective functions.

\section{Available Methods}

Council (1999) developed the LAK2 package to simulate lake-groundwater interaction with the three-dimensional finite-difference modular groundwater flow model (MODFLOW). LAK2 builds on the LAK1 computer package (Cheng and Anderson, 1993) and the reservoir simulation module RES1 (Fenske et. al., 1996). It handles lake-aquifer and lake-stream interactions, lake expansion and contraction, multiple inflow and outflow streams, and user specified stage-outflow relationships. Lake stage can be computed as steady-state, transient, or a linear function of time. MODLAKE, which is a MODFLOW simulation model that includes the LAK2 package, is used in this study to simulate stream/aquifer/reservoir flows.

A simple genetic algorithm (SGA) is a search procedure based on the mechanics of natural selection and natural genetics. It is mainly a population-based model that uses selection and recombination operators to search over a solution space in an attempt to locate the best solution. SGAs have been applied almost exclusively to singleobjective optimization problems. Srinivas and Deb (1995) proposed a nondominated 
sorting genetic algorithm (NSGA) for multiobjective optimization. NSGA uses a ranking selection method to emphasize current nondominated (pareto optimal) points and a sharing function method to maintain diversity in the population. In this paper we focus on how the NSGA is implemented to address the problem at hand. The fuzzy-penalty function method that was developed by Cheng and $\mathrm{Li}(1998)$ is used to implicitly handle constraints on state variables.

To address our multiobjective problem we use NSGA coupled with artificial neural networks (ANN). We use one ANN per state variable. An ANN can approximate complicated functions that are difficult to model mathematically or to evaluate numerically (Smith, 1993). We used the NeuralSIM ${ }^{\mathrm{TM}}$ commercial ANN package. Figure 2 shows the ANN-NSGA model processing.

\section{Results and Discussion}

MODLAKE simulated transient conditions using three 60-day stress periods. Decision variables include: pumping wells 1 and 2, stream diversions 1 and 2, reservoir diversion, and reservoir release. For three periods, this totals 18 decision variables. After each simulation, 21 state variables are recorded, seven for each stress period. These are heads at wells in confined and unconfined layers, two stream stages, and reservoir stage. A different ANN was trained for each state variable yielding 21 networks. Figure 3, predicted versus actual lake stage in period 1, shows a high linear correlation value $(\mathrm{R}=0.999)$. Similar results were found for all state variables.

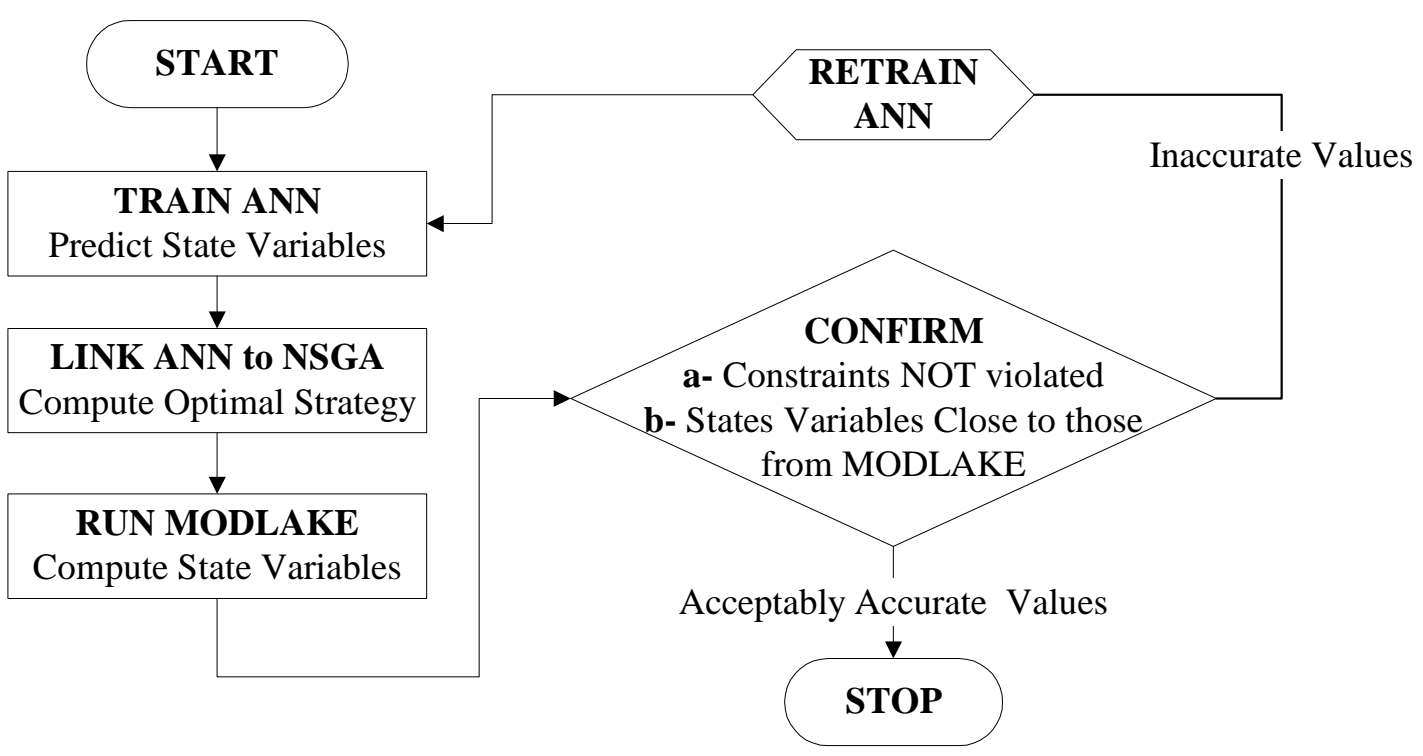

Figure 2. ANN-NSGA Model Processing.

For each scenario, the NSGA included the objective or fitness functions, constraints, and 21 linked ANNs. A binary coding was adopted in order to represent decision 
variables. A mutation probability of 0.01 and a crossover rate of 0.6 were used in the NSGA. The stopping criteria was set at 500 generations. For scenarios 1 and 2, the initial population size was set at 2758 individuals. It was set at 5794 individuals for scenario 3. We obtained these values via sizing criteria suggested by Mahfoud (1995).

Figures 4-6 show results. Linear correlation, $R$, is between 0.85 and 0.99 for the 21 state variables, indicating ANN is a reasonable predictor. Using the networks within the data range of this study guarantees a close prediction of system response.

The proposed ANN-NSGA model did not violate any constraints. This clearly proves that the fuzzy-logic penalty function method for handling constraints is quite efficient and robust. It is a powerful tool for constrained multiobjective optimization. The final product of all three scenarios is a set of trade-off curves that allow the manager to assess the relative importance of each objective.

\section{Conclusion}

A new simulation/optimization model based on artificial neural networks and genetic algorithm is presented. It is robustly able to simulate water flows and optimize different water management problems without violating any specified constraints. The model simultaneously addresses all significant flows in a dynamic hydraulically connected reservoir-stream-aquifer system and addresses multiple objectives.

Although the methods presented in this paper were developed for a conjunctive water use problem, the proposed methodology and formulation can be applied to any optimization problem.

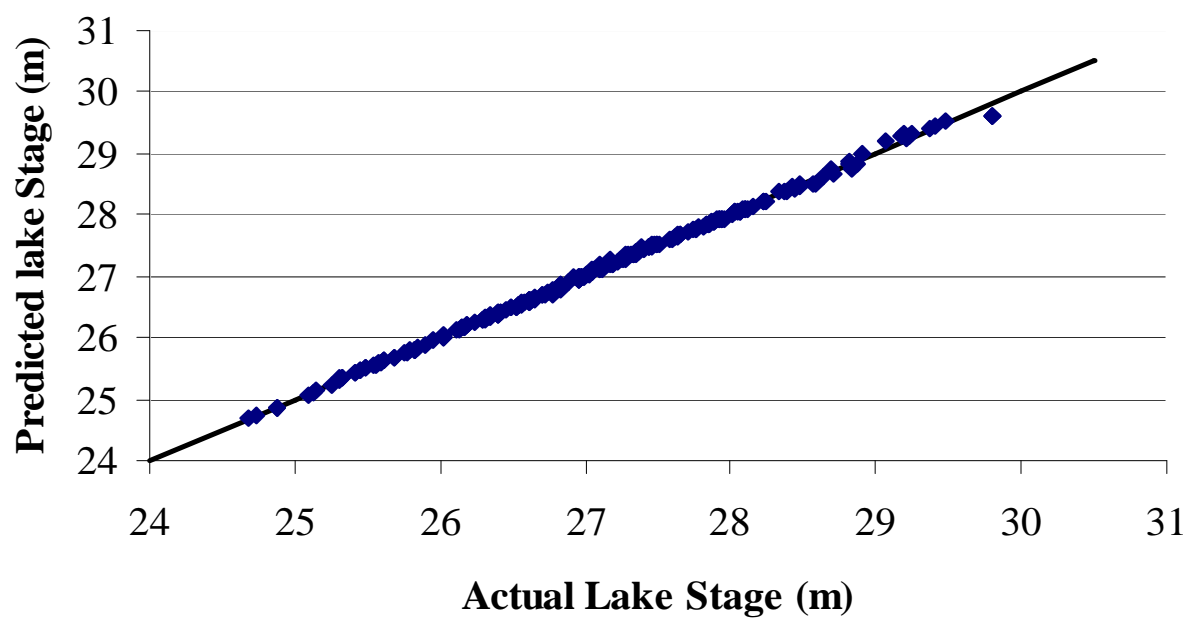

Figure 3. A Plot of Predicted vs. Actual Lake Stage. 


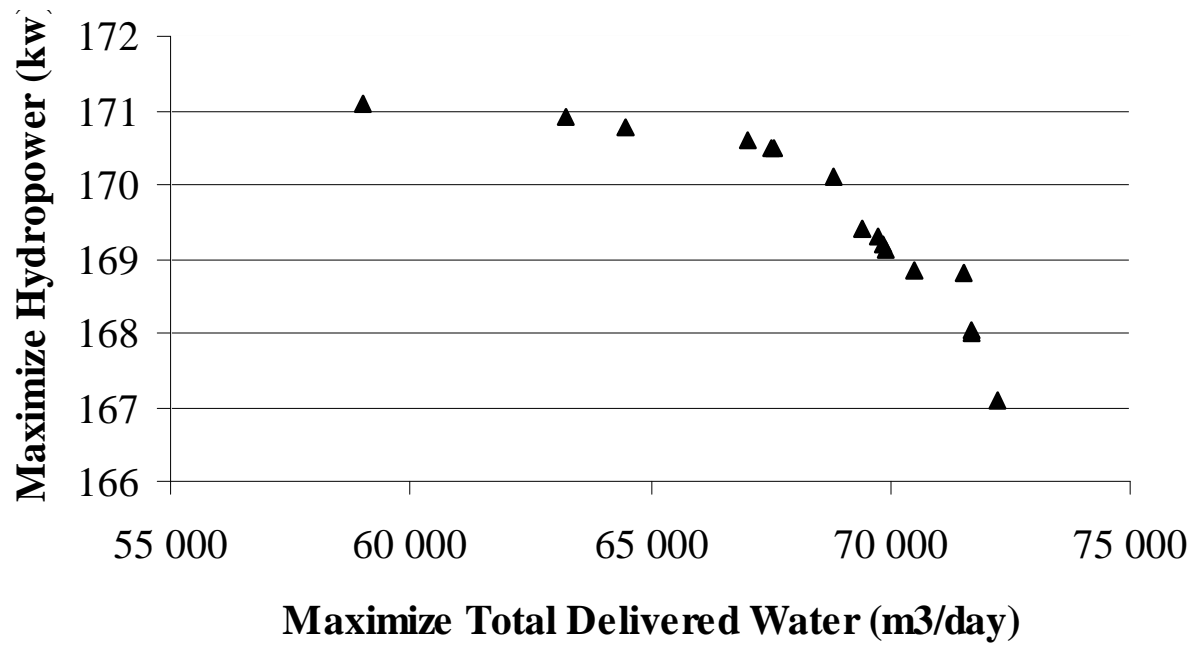

Figure 4. A Plot of Total Water Delivered vs. Hydropower for Scenario 1.

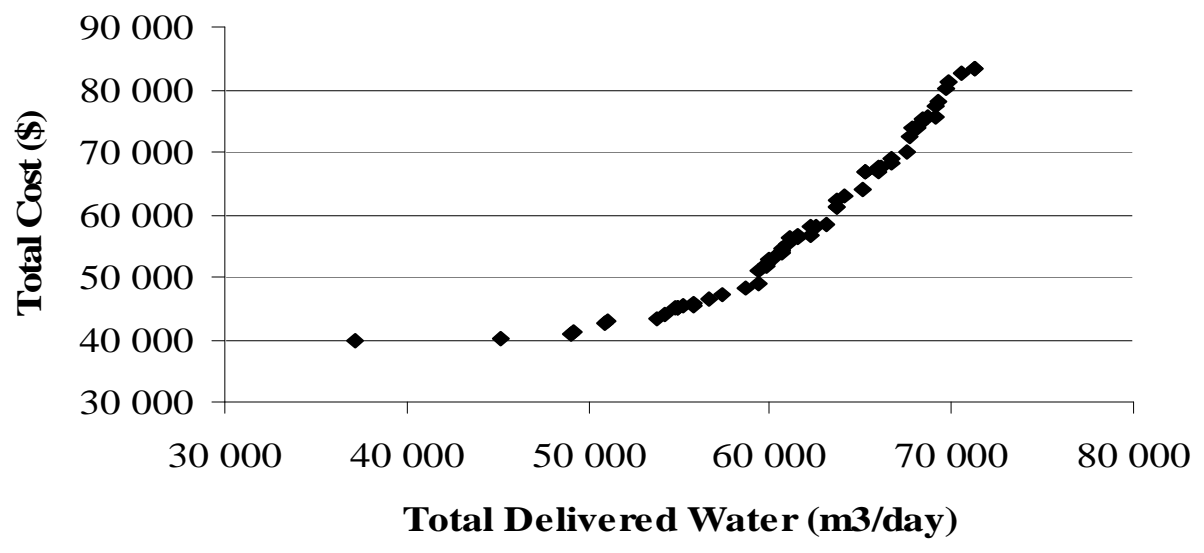

Figure 5. A Plot of Total Water Delivered vs. Total Cost for Scenario 2. 


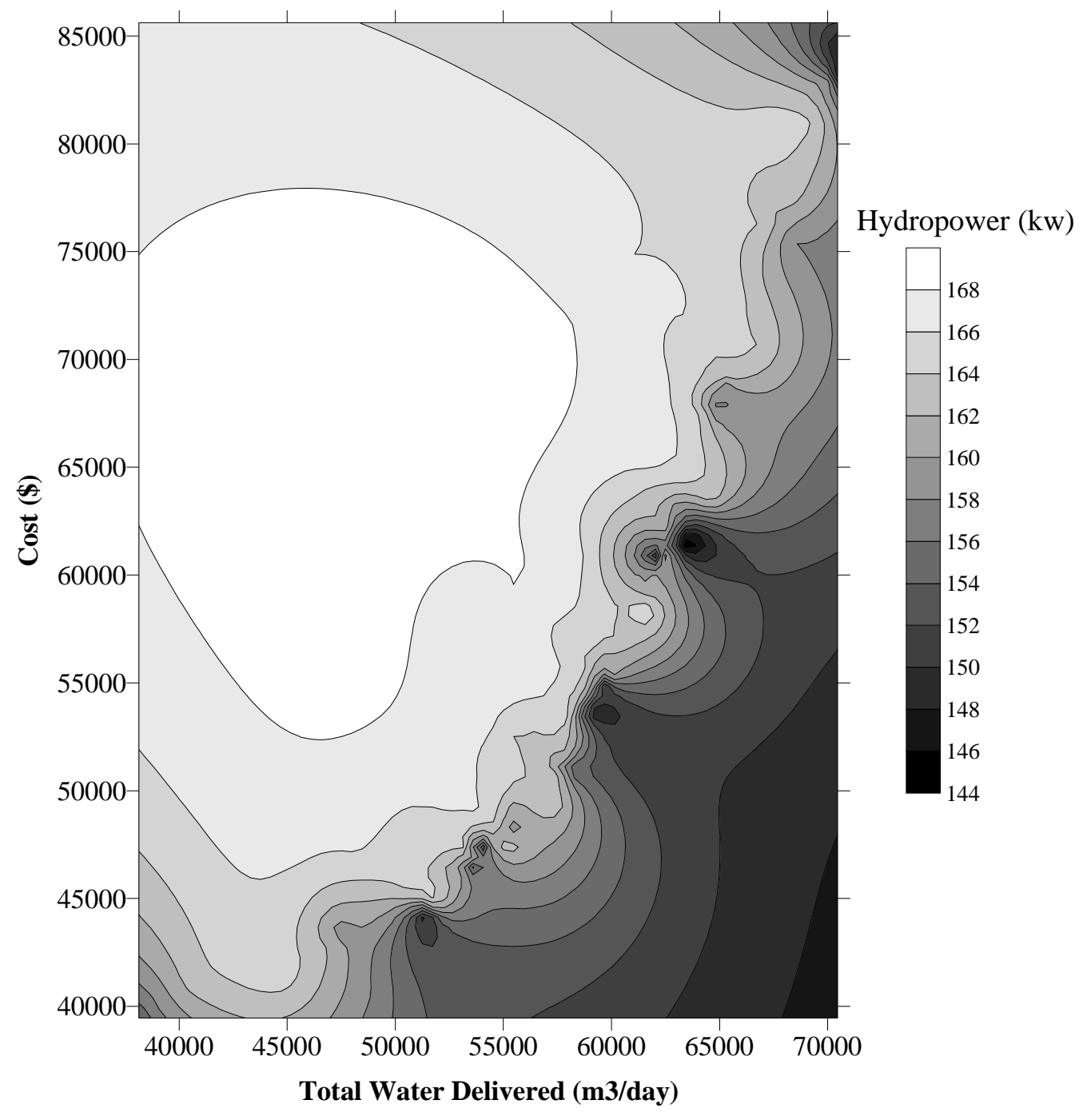

\section{References}

Figure 6. A Contour Map of all Scenario 3 objectives.

Belaineh, G., R.C. Peralta, and T.C. Hughes. (1999). "Simulation/optimization modeling for water resources management". Journal of Water Resources Planning and Management 125(3):154-161.

Cheng, F.Y. and D. Li. (1998). "Genetic algorithm development for multiobjective optimization of structures". American Institute of Aeronautics and Astonautics Journal 36(6):1105-1112.

Cheng, X. and M.P. Anderson. (1993). "Numerical simulation of ground-water interaction with lakes allowing for fluctuating lake levels." Ground Water 31(6):929-933.

Cieniawski, S.E., J.W. Eheart and S. Ranjithan. (1995). "Using genetic algorithms to solve a multiobjective groundwater monitoring problem." Water Resources Research 31(2):399-409.

Council, G.W. (1999). A lake package for MODFLOW (LAK2)--Documentation and user's manual, HSI Geotrans--A Tetra Tech Company, Sterling, Virginia. 
Ejaz, M.S. and R.C. Peralta. (1995). "Maximizing conjunctive use of surface and groundwater under surface water quality constraints." Advances in Water Resources 18(2):65-67.

Fenske, J.P., S.A. Leake and D.E. Prudic, (1996). "Documentation of a computer program (RES1) to simulate leakage from reservoirs using the modular-finitedifference-ground-water flow model (MODFLOW)," Open-File Report 96-364, US Geological Survey, Denver, Colorado.

Gharbi, A. and R.C. Peralta. (1994). "Integrated embedding optimization applied to SaltLake valley aquifer.” Water Resources Research 30(3):817-832.

Jones, L.C., R.C. Willis and W.W. Yeh. (1987). "Optimal control of non-linear groundwater hydraulics using differential dynamic programming." Water Resources Research 23(11):2097-2106.

Lettenmaier, D.P. and S.J. Burges. (1997). "Reliability of cyclic surface and groundwater storage systems for water supply: A preliminary assessment," Tech. Rep. 64, Department of Civil Engineering, University of Washington, Seattle.

Mahfoud, S.W. (1995). Population size and genetic drift in fitness sharing In Foundations of Genetic Algorithms 3, ed. D. Whitley and M.D. Vose, Morgan Kaufmann, San Francisco, 185-224.

McKinney, D.C. and M.D. Lin. (1994). "Genetic algorithm solution of groundwater management models." Water Resources Research 30(6):1897-1906.

Morel-Seytoux H.J. and C.M. Zhang. (1990). "The dynamics and mathematics of stream-aquifer-well interactions," Proceedings of the Tenth Annual American Geophysical Union: April 10-12, Colorado State University, Fort Collins, Colorado.

Mueller, F.A. and J.W. Male. (1993). "A management model for specification of groundwater withdrawal permits." Water Resources Research 29(5):1359-1368.

Peralta, R.C., R.R.A. Cantiller and J.E. Terry. (1995). "Optimal large-scale conjunctive water use planning-case study." Journal of Water Resources Planning and Management 21(6):471-478.

Peralta, R.C. and A. Aly. (1993). "US/REMAX Utah State model for optimizing management of stream/aquifer systems using the response matrix method," Report, BIE Department, Utah State University, Logan, Utah.

Peralta, R.C., A. Gharbi, L. Willardson and A. Peralta. (1990). Optimal conjunctive use of irrigation sources In Management of farm irrigation systems, G.J. Hoffman, T.A. Howell, and K.H. Solomon (ed.), American Society of Agricultural Engineering, St. Joseph, Michigan, 427-458.

Peralta, R.C., Kalwij, I.M., and Wu, S. (2003). "Practical Simulation / Optimization Modeling for Groundwater Quality and Quantity Management." In: MODFLOW and More 2003: Understanding through Modeling - Conference Proceedings, Poeter, Zheng, Hill \& Doherty. pp. $784-788$.

Peralta, R.C. and P.J. Killian. (1985). "Optimal regional potentiometric surface design: Least cost water supply/sustained groundwater yield." Transactions of the ASAE 28(4):1098-1107.

Reilly, T.E., O.L. Frank and G.D. Benett. (1987). The principle of superposition and its application in groundwater hydraulics, US Government Printing Office,

Washington, D.C. $₹$ Please include in the superposition chapter (maybe ch2 where first illustrated, and in chapter on RM 
Ritzel, B.J., J.W. Eheart and S. Ranjithan. (1994). "Using genetic algorithms to solve a multiple objective groundwater pollution containmant problem". Water Resources Research 30(5):1589-1603.

Rizzo, D.M. and D.E. Dougherty. (1994). "Characterization of aquifer properties using artificial neural networks: Neural Kriging." Water Resources Research 30(2):483-496.

Rogers, L.L., F.U. Dowla and V.M. Johnson. (1995). "Optimal field-scale groundwater remediation using neural networks and the genetic algorithm." Environmental Science and Technology 29(5):1145-1155.

Rogers, L.L. and F.U. Dowla. (1994). "Optimization of groundwater remediation using artificial neural networks with parallel solute transport modeling." Water Resources Research 30(2):457-481.

Smith, M. (1993). Neural networks for statistical modeling, Van Nostrand Reinhold, New York.

Srinivas, N. and K. Deb. (1995). "Multiobjective optimization using nondominated sorting in genetic algorithms." Evolutionary Computation 2(3):221-248.

SSOL (2003) "SOMOS: Simulation / Optimization Modeling System.” User's

Manual. Systems Simulation / Optimization Laboratory. Department of

Biological and Irrigation Engineering, Utah State University, Utah.

Takahashi, S. and R.C. Peralta. (1995).” Optimal perennial yield planning for complex non-linear aquifers: Methods and examples." Advances in Water Resources 18:49-62.

Wang, C., B. Mortazavi, W.K. Liang, N.Z. Sun and W.W.G. Yeh. (1995). "Model development for conjunctive use study of the San Jacinto Basin California." Water Resources Bulletin 31(2):227-242.

Yan, J. and K.R. Smith. (1994). "Simulation of integrated surface water and groundwater systems--Model formulation." Water Resources Bulletin 30(5):879890. 